\title{
Sagittal craniosynostosis: a utility outcomes study
}

\author{
Victoria Kuta, BScH, ${ }^{1}$ P. Daniel McNeely, MD, FRCSC, ${ }^{2}$ Simon Walling, MBChB, FRCSC, ${ }^{2}$ and \\ Michael Bezuhly, MD, FRCSC ${ }^{3}$
}

\begin{abstract}
${ }^{1}$ Faculty of Medicine; ' ${ }^{2}$ ivision of Neurosurgery, IWK Health Centre; and ${ }^{3}$ Division of Plastic \& Reconstructive Surgery, IWK Health Centre, Dalhousie University, Halifax, Nova Scotia, Canada
\end{abstract}

OBJECTIVE Sagittal craniosynostosis results in a characteristic scaphocephalic head shape that is typically corrected surgically during a child's 1st year of life. The authors' objective was to determine the potential impact of being born with sagittal craniosynostosis by using validated health state utility assessment measures.

\begin{abstract}
METHODS An online utility assessment was designed to generate health utility scores for scaphocephaly, monocular blindness, and binocular blindness using standardized utility assessment tools, namely the visual analog scale (VAS) and the standard gamble (SG) and time trade-off (TTO) tests. Utility scores were compared between health states using the Wilcoxon and Kruskal-Wallis tests. Univariate regression was performed using age, sex, income, and education as independent predictors of utility scores.
\end{abstract}

RESULTS Over a 2-month enrollment period, 122 participants completed the online survey. One hundred eighteen participants were eligible for analysis. Participants rated scaphocephaly due to sagittal craniosynostosis with significantly higher ( $p$ <.001) median utility scores (VAS 0.85, IQR 0.76-0.95; SG 0.92, IQR 0.84-0.98; TTO 0.91, IQR 0.84-0.95) than both monocular blindness (VAS 0.60, IQR 0.50-0.70; SG 0.84, IQR 0.68-0.94; TTO 0.84, IQR 0.67-0.91) and binocular blindness (VAS 0.25, IQR 0.20-0.40; SG 0.51, IQR 0.18-0.79; TTO 0.55, IQR 0.36-0.76). No differences were noted in utility scores based on participant age, sex, income, or education.

CONCLUSIONS Using objective health state utility scores, authors of the current study demonstrated that the preoperatively perceived burden of scaphocephaly in a child's 1st year of life is less than that of monocular blindness. These relatively high utility scores for scaphocephaly suggest that the burden of disease as perceived by the general population is low and should inform surgeons' discussions when offering morbid corrective surgery, particularly when driven by aesthetic concerns.

https://thejns.org/doi/abs/10.3171/2017.2.PEDS16567

KEY WORDS health utility outcomes; scaphocephaly; sagittal craniosynostosis; visual analog scale; standard gamble; time trade-off; craniofacial

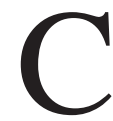
RANIOSYNOSTOSIS, a congenital anomaly involving the early fusion of cranial bones, affects 1 in 2000-3000 live births. ${ }^{10,22,26,50}$ The most common form of single-suture craniosynostosis involves the sagittal suture, resulting in a typical scaphocephalic head shape with elongation in the anteroposterior dimension and bitemporoparietal narrowing. 13,24 While this condition leads to an abnormal skull shape, major long-term impairment in vision, memory, and other cognitive functions is uncommon given compensatory growth of the skull and brain along other sutures. ${ }^{25,46}$ Although the disorder's impact on neurocognitive development remains in question, children with sagittal craniosynostosis may be faced with social and psychological barriers that negatively impact their self-esteem and social function because of their scaphocephalic appearance..$^{31,41}$ Although reports have documented the psychosocial aspects of scaphocephaly, no study to date has quantified the perceived burden of sagittal craniosynostosis and scaphocephaly by using standardized methods of obtaining health utility scores. Utility scores such as the visual analog scale (VAS), standard gamble (SG) test, and time trade-off (TTO) test allow for a better

ABBREVIATIONS SG = standard gamble; TTO = time trade-off; VAS = visual analog scale ACCOMPANYING EDITORIAL See pp 111-112. DOI: 10.3171/2017.3.PEDS1758.

SUBMITTED September 30, 2016. ACCEPTED February 1, 2017.

INCLUDE WHEN CITING Published online May 19, 2017; DOI: 10.3171/2017.2.PEDS16567. 
understanding of the disease burden and can aid decision making regarding the need for intervention. ${ }^{44,47,48}$ The purpose of the present study was to measure the health state of a diagnosis of sagittal craniosynostosis by using utility scores in an attempt to objectively compare the burden of a scaphocephalic head shape with other recognized debilitating health states, namely blindness. By quantifying the perceived psychosocial burden associated with sagittal craniosynostosis among the general population, we hoped to better understand the conflict felt by families when offered a potentially morbid corrective surgery in a child's 1 st year of life for an aesthetic indication.

\section{Methods}

Institutional research ethics approval was obtained for the study. All prospective participants signed an electronic informed consent, and the parent of the child whose photograph was used in the study signed a written consent for use of their child's photograph for research and publication purposes.

A prospective random sample of the general population was included in our study. An open-enrollment, online health utility assessment survey was designed using the Opinio survey tool (version 7.1.2, ObjectPlanet Inc.). A classified online advertisement website (http://www. kijiji.com) was used to recruit participants from the general public, while undergraduate medical students were recruited on a voluntary basis via institutional email. Responses from unique Internet Protocol (IP) addresses were collected to avoid multiple entries. Participants completed anonymous demographic and health state questionnaires in addition to utility assessments. To evaluate the study participants' comprehension, as well as to facilitate comparison with previously published studies, monocular and binocular blindness scenarios were used. Only participants who correctly rated binocular blindness with a lower utility score than monocular blindness were included in the analysis.

Participants were presented with a health-state description and photograph of a patient with binocular blindness, monocular blindness, and a typical scaphocephalic head shape (cephalic index 0.67) due to sagittal craniosynostosis (Fig. 1). The health-state description of the patient with scaphocephaly emphasized the potential progression of the deformity with age if left uncorrected. Participants were asked to imagine themselves as the patient and to complete a VAS, SG test, and TTO test to assess the health-related quality of life of each of the presented patients (monocular blindness, binocular blindness, sagittal craniosynostosis). All 3 of these utility measures were used to reduce the drawbacks of each individual test.

As previously described, ${ }^{5,16,36}$ for the VAS, participants were asked to score a value ranging from 0 (death) to 100 (perfect health) while imagining him- or herself as the patient in the given health state. The utility health state was calculated as follows: score/100. On the TTO test, participants were asked to choose between living a specified number of years in the described health state and giving up a certain number of years of life to have perfect health. Sequential years of life were presented until the
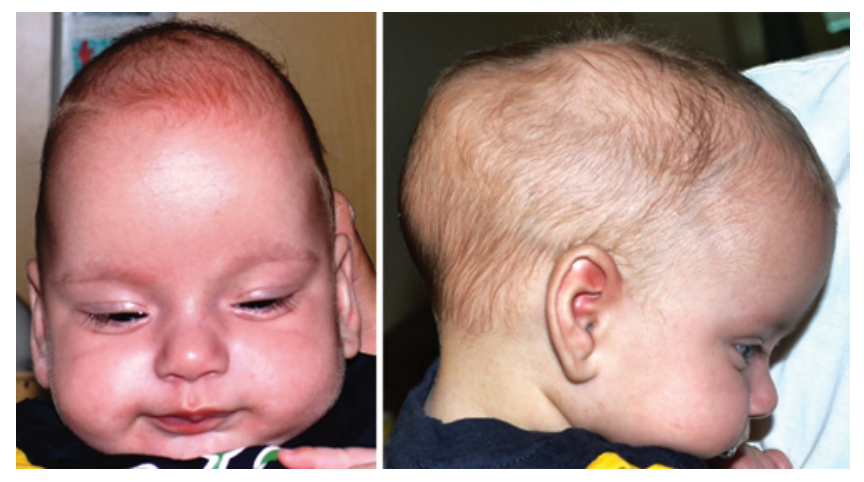

FIG. 1. Representative anterior (left) and lateral (right) images of a patient with sagittal craniosynostosis that accompanied the clinical scenario. The clinical scenario read as follows: "Imagine yourself like Peter. I have an abnormal shape to my skull. My head will continue to grow long and narrow. I have normal intelligence and development. I have no problems with regular activities. I have no headaches or discomfort." Figure is available in color online only.

indifference point was found, that is, the point at which the participant is no longer willing to trade years of life to achieve perfect health. The utility value was calculated as follows: (number of years in the described health state - number of years traded off at the indifference point)/ (number of years in the described health state). Lastly, for the SG score, study volunteers were asked to choose between remaining in a given health state and gambling on a state in which there is a stated probability of perfect health and a stated probability of death. Sequential probabilities of perfect health and death were presented until the indifference point was found, that is, the point at which the participant is indifferent to taking the gamble or remaining in the described health state. The utility score was obtained using the following formula: (1.00 - risk of death at indifference point)/100..$^{5,16,36}$

\section{Statistical Analysis}

Statistical analyses were performed using the opensource statistical computing program $\mathrm{R}$ for Mac OS X 10.9, version 3.3.1 (Bell Laboratories). Utility score distributions were tested for normality using the Shapiro-Wilk test. For utility scores with nonnormal distributions, the nonparametric Wilcoxon and Kruskal-Wallis tests were used, with median and interquartile ranges reported. To account for family-wise error rate bias, noted significance was reduced to $p<0.01$. Using age, race, and education as independent predictors of each of the utility scores (VAS, TTO, and SG) for scaphocephaly, a linear regression was performed. Values of $p<0.05$ were considered statistically significant for these analyses.

\section{Results}

A total of 122 participants completed the online survey over a 2-month enrollment period. We excluded 4 participants who indicated that they did not understand the survey by assigning a higher health utility score to binocular blindness than monocular blindness. These excluded participants did not differ from the 118 participants included in the analysis in terms of age, sex, or education. 
TABLE 1. Participant demographics

\begin{tabular}{lc}
\hline \multicolumn{1}{c}{ Characteristic } & No. $(\%)$ \\
\hline Mean age in yrs & $31.4 \pm 14.1$ \\
\hline Sex & $66(55.9)$ \\
Female & $48(40.7)$ \\
Male & $4(3.4)$ \\
Prefer not to answer & \\
Education & $5(4.2)$ \\
High school & $7(5.9)$ \\
Some college & $21(17.8)$ \\
College graduate & $43(36.4)$ \\
Medical student & $25(21.2)$ \\
Graduate or professional degree & $17(14.4)$ \\
Prefer not to answer & \\
Income & $57(48.3)$ \\
$>\$ 50,000$ & $25(21.2)$ \\
$<\$ 50,000$ & $36(30.5)$ \\
Prefer not to answer & \\
Race & $86(72.9)$ \\
White & $2(1.7)$ \\
African American & $4(3.4)$ \\
Asian & $1(0.8)$ \\
Native American & $2(1.7)$ \\
Hispanic & $3(2.5)$ \\
Other & $20(16.9)$ \\
Prefer not to answer &
\end{tabular}

Among those included in the study, there were slightly more female $(55.9 \%)$ versus male participants (44.1\%). The majority of respondents were well educated, with $81.3 \%$ attending some form of postsecondary school. Of the participants, $36.4 \%$ were medical students. Most of the participants identified as white $(72.9 \%)$, and the average age of participants was $31.4 \pm 14.1$ years (Table 1). None of the participants had a history of scaphocephaly/sagittal craniosynostosis or knew of someone with the condition. The median health status of participants was 0.95 (IQR 0.90-0.95).

The VAS (0.60, IQR 0.50-0.70), TTO (0.84, IQR $0.67-0.91)$, and SG (0.84, IQR 0.68-0.94) utility scores for monocular blindness were all significantly $(\mathrm{p}<0.01)$ different from the corresponding utility scores for binocular blindness (VAS 0.25, IQR 0.20-0.40; TTO 0.55, IQR 0.36-0.76; SG 0.51, IQR 0.18-0.79). The utility scores for scaphocephaly (VAS 0.85, IQR 0.76-0.95; TTO 0.91, IQR 0.84-0.95; SG 0.92, IQR 0.84-0.98) were all significantly higher $(\mathrm{p}<0.001)$ than those for monocular blindness (Table 2). When analyzing the health utility scores for scaphocephaly, an SG of 0.92 translates to a willingness to undergo a procedure that has an $8 \%$ risk of death to attain a state of perfect health. Similarly, a TTO score of 0.91 can be interpreted as a willingness to theoretically sacrifice 3 years of life to live the remaining years in a state of perfect health.

Utility scores did not significantly differ between male and female participants or when comparing the answers of white versus non-white participants. Additionally, no significant difference was found between the reported utility
TABLE 2. Utility scores of monocular blindness versus scaphocephaly

\begin{tabular}{cccc}
\hline Utility Score & Monocular Blindness & Scaphocephaly & $p$ Value \\
\hline VAS & $0.60(0.50-0.70)$ & $0.85(0.76-0.95)$ & $<0.001$ \\
SG & $0.84(0.68-0.94)$ & $0.92(0.84-0.98)$ & $<0.001$ \\
TTO & $0.84(0.67-0.91)$ & $0.91(0.84-0.95)$ & $<0.001$ \\
\hline
\end{tabular}

Values expressed as the median (IQR).

scores from medical students and those of the general population (Table 3). The univariate linear regression showed no statistical significance using age, sex, income, or education as predictors of utility scores for scaphocephaly.

\section{Discussion}

Sagittal craniosynostosis is the most common form of craniosynostosis, accounting for $45 \%$ of nonsyndromic cases. ${ }^{10,13,21}$ While studies have found the overall quality of life to be lower in syndromic and complex craniosynostosis patients, $, 3,12$ there has been little research on the health utility of nonsyndromic sagittal craniosynostosis. In this study we aimed to quantify the associated burden of scaphocephaly as perceived by the public in an effort to help physicians address families' concerns regarding indications for treatment of this form of craniosynostosis.

According to results obtained in our study, participants equate a scaphocephalic head shape with a higher health utility state than monocular blindness, a well-recognized impairment. Theoretically, participants would be willing to accept an $8 \%$ risk of death or give up to 3 years of their life to live in a state of perfect health without scaphocephaly. Our utility scores for monocular and binocular blindness were similar to those in previous studies, allowing us to compare our results with the utility scores for other health states (Table 4). ${ }^{1,5,7,15-18,32-39}$ On the basis of previously published utility scores for other health states, scaphocephaly appears more comparable to largely aesthetic deformities such as breast ptosis, microtia without hearing loss, and massive weight loss requiring body contouring. ${ }^{5}$

TABLE 3. Utility scores by sex, participant type, and race

\begin{tabular}{cccc}
\hline Utility Score & Group 1 & Group 2 & p Value \\
\hline Sex & Female & Male & \\
\hline VAS & $0.85(0.75-0.95)$ & $0.85(0.80-0.90)$ & 0.842 \\
\hline SG & $0.92(0.84-0.98)$ & $0.92(0.84-0.98)$ & 0.236 \\
\hline TTO & $0.92(0.84-0.95)$ & $0.92(0.82-0.97)$ & 0.474 \\
\hline Participant type & Medical Student & General Population & \\
\hline VAS & $0.85(0.80-0.95)$ & $0.85(0.75-0.91)$ & 0.135 \\
\hline SG & $0.95(0.89-0.99)$ & $0.92(0.82-0.98)$ & 0.418 \\
\hline TTO & $0.91(0.86-0.96)$ & $0.91(0.84-0.95)$ & 0.365 \\
\hline Race & White & Non-White & \\
\hline VAS & $0.86(0.80-0.95)$ & $0.80(0.79-0.85)$ & 0.553 \\
\hline SG & $0.92(0.84-0.98)$ & $0.80(0.53-0.93)$ & 0.501 \\
\hline TTO & $0.92(0.84-0.95)$ & $0.84(0.73-0.95)$ & 0.321 \\
\hline
\end{tabular}

Values expressed as the median (IQR). 
TABLE 4. Utility scores of other health states

\begin{tabular}{lccc}
\hline & \multicolumn{3}{c}{ Utility Score } \\
\cline { 2 - 4 } \multicolumn{1}{c}{ Health State } & VAS & TTO & SG \\
\hline Aging neck after massive weight loss & 0.89 & 0.94 & 0.95 \\
Scaphocephaly & 0.85 & 0.92 & 0.91 \\
Nipple areolar complex deformity after breast & 0.84 & 0.92 & 0.92 \\
reconstruction & & & \\
Microtia w/o deafness & 0.83 & 0.89 & 0.91 \\
Arm laxity after massive weight loss & 0.80 & 0.91 & 0.94 \\
Nasal deformity after rhinoplasty & 0.80 & 0.90 & 0.91 \\
Breast ptosis & 0.80 & 0.87 & 0.90 \\
Massive weight loss requiring body contouring & 0.79 & 0.89 & 0.89 \\
Thigh laxity after massive weight loss & 0.77 & 0.90 & 0.89 \\
Unilat mastectomy defect & 0.75 & 0.87 & 0.86 \\
Microtia w/ deafness & 0.74 & 0.83 & 0.86 \\
Bilat mastectomy defect & 0.70 & 0.85 & 0.86 \\
Severe breast hypertrophy & 0.70 & 0.85 & 0.88 \\
Cleft lip \& palate & 0.69 & 0.85 & 0.84 \\
Monocular blindness & 0.59 & 0.83 & 0.76 \\
Unilat facial paralysis & 0.56 & 0.78 & 0.79 \\
Unilat lower leg lymphedema & 0.50 & 0.76 & 0.76 \\
Hand amputation & NR & 0.80 & 0.72 \\
Severe facial disfigurement & 0.46 & 0.68 & 0.66 \\
Binocular blindness & 0.32 & 0.48 & 0.53 \\
Severe facial burn & NR & 0.57 & 0.53 \\
\hline & & &
\end{tabular}

$\mathrm{NR}=$ not reported

While the aesthetic deformity associated with sagittal craniosynostosis is evident to the casual observer, the association with long-term neurological impairment remains controversial., $111,19,20,23,25,40-43,49$ Increased intracranial pressure and associated cognitive impairment is common in syndromic and complex cases involving fusion of more than one suture; however, compensatory growth in sagittal craniosynostosis patients appears to prevent cognitive debilitation in most affected cases. ${ }^{45}$ In fact, intracranial volume has been found to increase as a function of time in patients with uncorrected sagittal synostosis. ${ }^{28,29}$ For those nonsyndromic patients who do develop intracranial hypertension, corrective surgery has not been found to correct associated impairments. ${ }^{13,49}$ Some standard-ofcare guidelines dismiss potential cognitive impairment as an indication for surgery, based on available low-level evidence. ${ }^{25}$ Despite this inconclusive evidence, most parents opt for corrective surgery to remodel the skull and allow for normal head growth in their child. ${ }^{8}$ This finding suggests that scaphocephaly correction in nonsyndromic cases is performed largely for aesthetic reasons, with the aim of improving the psychosocial experiences of the child throughout life.

Boltshauser et al. studied the psychosocial experiences of children with uncorrected scaphocephaly through parent reports on quality of life. ${ }^{4}$ Parents reported that their affected children were well adjusted with a normal healthrelated quality of life; however, they also described their affected children as less joyful, happy, and confident than healthy children. While this may suggest negative effects on emotional functioning, it is important to note that all scores fell within normal ranges. Our study builds on these findings, presenting the health utility scores of scaphocephaly as determined by an unbiased random sample of the population rather than by parents of the affected child.

In the current study, participants were asked to determine the health utility of scaphocephaly in the absence of any neurological deficits. This allowed us to focus solely on the aesthetic aspects of the condition. The image we chose to display in this survey represented a patient with the average preoperative cephalic index commonly reported for sagittal craniosynostosis patients. ${ }^{6,14,27,30}$ The high utility scores for scaphocephaly suggest that improvement in the aesthetic deformity in the 1st year of life may not be the principal driver for surgical correction. Instead, we speculate that parents choose to submit their child to an invasive surgery to avoid progression of the deformity later in life. Although the current study does not allow us to definitively prove this theory, our findings underscore the potential for decisional conflict among families faced with the prospect of surgical correction for their infant child. The decision to proceed with surgery could be made easier for parents, we speculate, by presenting them with photographs of adults with uncorrected sagittal craniosynostosis to provide them with a sense of the deformity's potential progression. In the current study we did not include photographs of untreated adults given our concern that different responses would be obtained depending on the sequence in which the two very similar scenarios were presented online. For example, if the scenario of the nonoperated child was presented after that of the untreated adult, respondents would likely rate the former cranial difference as even less severe than in the current report, again failing to reflect the clinical experience. Thus, the current report serves as a proof of principle for further studies, including a randomized controlled trial in which parents of children with sagittal craniosynostosis are or are not presented with photographs of an untreated adult during the initial clinic visit to determine if this reduces their decisional conflict. Ultimately, this study points to the need for surgeons to hold frank discussions with families that balance aesthetic, psychosocial, and cognitive concerns against the potential risks of morbidity and mortality associated with surgery.

This study is not without its limitations. As mentioned above, given ongoing compensatory cranial growth, the image used in this study does not accurately represent the progression of the severity of the deformity into adulthood. While participants were informed that the head would continue to grow long and narrow, an image of the progression would probably have resulted in lower utility scores. However, our aim was to create, as best as possible, the scenario faced preoperatively by parents of children with sagittal craniosynostosis in the 1st year of life. In addition, although recruitment was designed to obtain a sample of the general public, our study may not accurately reflect the broad population with which patients would ultimately interact. The majority of our respondents were healthy, young, educated, and white. Finally, this study did not include respondents who were themselves born with sagittal craniosynostosis. Future studies should aim to compare utility scores reported by patients with uncorrected and corrected sagittal craniosynostosis with those 
reported by the general population. Despite these limitations, our study offers important insight for physicians and families when discussing corrective surgery for scaphocephaly due to sagittal craniosynostosis.

\section{Conclusions}

Using objective health state utility scores, we showed that the perceived burden of sagittal craniosynostosis and scaphocephaly is less than that of monocular blindness, a well-recognized functional impairment. These relatively high utility scores for scaphocephaly suggest that the burden of disease as perceived by the general population in a child's 1st year of life may not justify morbid corrective surgery when performed for aesthetic purposes alone.

\section{References}

1. Alolabi N, Chuback J, Grad S, Thoma A: The utility of hand transplantation in hand amputee patients. J Hand Surg Am 40:8-14, 2015

2. Bannink N, Maliepaard M, Raat H, Joosten KF, Mathijssen IM: Health-related quality of life in children and adolescents with syndromic craniosynostosis. J Plast Reconstr Aesthet Surg 63:1972-1981, 2010

3. Bannink N, Maliepaard M, Raat H, Joosten KF, Mathijssen IM: Obstructive sleep apnea-specific quality of life and behavioral problems in children with syndromic craniosynostosis. J Dev Behav Pediatr 32:233-238, 2011

4. Boltshauser E, Ludwig S, Dietrich F, Landolt MA: Sagittal craniosynostosis: cognitive development, behaviour, and quality of life in unoperated children. Neuropediatrics 34:293-300, 2003

5. Byun S, Hong P, Bezuhly M: Public perception of the burden of microtia. J Craniofac Surg 27:1665-1669, 2016

6. Christophis P, Jünger TH, Howaldt HP: Surgical correction of scaphocephaly: experiences with a new procedure and follow-up investigations. J Maxillofac Surg 29:33-38, 2001

7. Chuback J, Yarascavitch B, Yarascavitch A, Kaur MN, Martin S, Thoma A: Measuring utilities of severe facial disfigurement and composite tissue allotransplantation of the face in patients with severe face and neck burns from the perspectives of the general public, medical experts and patients.

Burns 41:1524-1531, 2015

8. Chummun S, McLean NR, Flapper WJ, David DJ: The management of nonsyndromic, isolated sagittal synostosis. J Craniofac Surg 27:299-304, 2016

9. Cohen SR, Cho DC, Nichols SL, Simms C, Cross KP, Burstein FD: American society of maxillofacial surgeons outcome study: preoperative and postoperative neurodevelopmental findings in single-suture craniosynostosis. Plast Reconstr Surg 114:841-849, 2004

10. Cornelissen M, Ottelander Bd, Rizopoulos D, van der Hulst R, Mink van der Molen A, van der Horst C, et al: Increase of prevalence of craniosynostosis. J Craniomaxillofac Surg 44:1273-1279, 2016

11. Da Costa AC, Anderson VA, Savarirayan R, Wrennall JA, Chong DK, Holmes AD, et al: Neurodevelopmental functioning of infants with untreated single-suture craniosynostosis during early infancy. Childs Nerv Syst 28:869-877, 2012

12. de Jong T, Maliepaard M, Bannink N, Raat H, Mathijssen IM: Health-related problems and quality of life in patients with syndromic and complex craniosynostosis. Childs Nerv Syst 28:879-882, 2012

13. Garza RM, Khosla RK: Nonsyndromic craniosynostosis. Semin Plast Surg 26:53-63, 2012

14. Guimarães-Ferreira J, Gewalli F, David L, Olsson R, Friede
H, Lauritzen CG: Clinical outcome of the modified pi-plasty procedure for sagittal synostosis. J Craniofac Surg 12:218226, 2001

15. Ibrahim AM, Sinno HH, Izadpanah A, Vorstenbosch J, Dionisopoulos T, Markarian MK, et al: Mastopexy for breast ptosis: utility outcomes of population preferences. Plast Surg (Oakv) 23:103-107, 2015

16. Ibrahim AM, Sinno HH, Izadpanah A, Vorstenbosch J, Dionisopoulos T, Mureau MA, et al: Nipple-areolar complex reconstruction following postmastectomy breast reconstruction: a comparative utility assessment study. Plast Reconstr Surg Glob Open 3:e380, 2015

17. Ibrahim AM, Sinno HH, Izadpanah A, Vorstenbosch J, Dionisopoulos T, Lee BT, et al: Population preferences of undergoing brachioplasty for arm laxity. Ann Plast Surg 73 (Suppl 2):S149-S152, 2014

18. Izadpanah A, Sinno H, Vorstenbosch J, Lee BT, Lin SJ: Thigh laxity after massive weight loss: a utilities outcomes assessment. Ann Plast Surg 71:304-307, 2013

19. Kapp-Simon KA, Speltz ML, Cunningham ML, Patel PK, Tomita T: Neurodevelopment of children with single suture craniosynostosis: a review. Childs Nerv Syst 23:269-281, 2007

20. Knight SJ, Anderson VA, Spencer-Smith MM, Da Costa AC: Neurodevelopmental outcomes in infants and children with single-suture craniosynostosis: a systematic review. Dev Neuropsychol 39:159-186, 2014

21. Kolar JC: An epidemiological study of nonsyndromal craniosynostoses. J Craniofac Surg 22:47-49, 2011

22. Lajeunie E, Le Merrer M, Bonaïti-Pellie C, Marchac D, Renier D: Genetic study of nonsyndromic coronal craniosynostosis. Am J Med Genet 55:500-504, 1995

23. Magge SN, Westerveld M, Pruzinsky T, Persing JA: Longterm neuropsychological effects of sagittal craniosynostosis on child development. J Craniofac Surg 13:99-104, 2002

24. Mann RJ, Burton ME: Treatment of cranial synostosis: the directive growth approach. J Craniofac Surg 25:e361-e363, 2014

25. Mathijssen IMJ: Guideline for care of patients with the diagnoses of craniosynostosis: working group on craniosynostosis. J Craniofac Surg 26:1735-1807, 2015

26. Mendoza CS, Safdar N, Okada K, Myers E, Rogers GF, Linguraru MG: Personalized assessment of craniosynostosis via statistical shape modeling. Med Image Anal 18:635-646, 2014

27. Panchal J, Marsh JL, Park TS, Kaufman B, Pilgram T, Huang SH: Sagittal craniosynostosis outcome assessment for two methods and timings of intervention. Plast Reconstr Surg 103:1574-1584, 1999

28. Persing JA: Discussion: Age at the time of surgery and maintenance of head size in nonsyndromic sagittal craniosynostosis. Plast Reconstr Surg 137:1566-1567, 2016

29. Posnick JC, Lin KY, Chen P, Armstrong D: Sagittal synostosis: quantitative assessment of presenting deformity and surgical results based on CT scans. Plast Reconstr Surg 92:1015-1024, 1225-1226, 1993

30. Ruiz-Correa S, Sze RW, Starr JR, Lin HT, Speltz ML, Cunningham ML, et al: New scaphocephaly severity indices of sagittal craniosynostosis: a comparative study with cranial index quantifications. Cleft Palate Craniofac J 43:211-221, 2006

31. Singh VP, Moss TP: Psychological impact of visible differences in patients with congenital craniofacial anomalies. Prog Orthod 16:5, 2015

32. Sinno H, Izadpanah A, Tahiri Y, Christodoulou G, Thibaudeau S, Williams HB, et al: The impact of living with severe lower extremity lymphedema: a utility outcomes score assessment. Ann Plast Surg 73:210-214, 2014

33. Sinno H, Izadpanah A, Thibaudeau S, Christodoulou G, 
Lin SJ, Dionisopoulos T: An objective assessment of the perceived quality of life of living with bilateral mastectomy defect. Breast 22:168-172, 2013

34. Sinno H, Izadpanah A, Thibaudeau S, Christodoulou G, Tahiri Y, Slavin SA, et al: The impact of living with a functional and aesthetic nasal deformity after primary rhinoplasty: a utility outcomes score assessment. Ann Plast Surg 69:431-434, 2012

35. Sinno H, Izadpanah A, Vorstenbosch J, Dionisopoulos T, Ibrahim AM, Tobias AM, et al: Living with a unilateral mastectomy defect: a utility assessment and outcomes study. J Reconstr Microsurg 30:313-318, 2014

36. Sinno H, Tahiri Y, Thibaudeau S, Izadpanah A, Christodoulou G, Lin SJ, et al: Cleft lip and palate: an objective measure outcome study. Plast Reconstr Surg 130:408-414, 2012

37. Sinno H, Thibaudeau S, Izadpanah A, Tahiri Y, Christodoulou G, Zuker R, et al: Utility outcome scores for unilateral facial paralysis. Ann Plast Surg 69:435-438, 2012

38. Sinno H, Thibaudeau S, Tahiri Y, Mok E, Christodoulou G, Lessard L, et al: Utility assessment of body contouring after massive weight loss. Aesthetic Plast Surg 35:724-730, 2011

39. Sinno HH, Ibrahim AM, Izadpanah A, Thibaudeau S, Christodoulou G, Tahiri Y, et al: Utility outcome assessment of the aging neck following massive weight loss. Otolaryngol Head Neck Surg 147:26-32, 2012

40. Speltz ML, Collett BR, Wallace ER, Starr JR, Cradock MM, Buono L, et al: Intellectual and academic functioning of school-age children with single-suture craniosynostosis. Pediatrics 135:e615-e623, 2015

41. Speltz ML, Collett BR, Wallace ER, Kapp-Simon K: Behavioral adjustment of school-age children with and without single-suture craniosynostosis. Plast Reconstr Surg 138:435-445, 2016

42. Speltz ML, Kapp-Simon K, Collett B, Keich Y, Gaither R, Cradock MM, et al: Neurodevelopment of infants with single-suture craniosynostosis: presurgery comparisons with case-matched controls. Plast Reconstr Surg 119:1874-1881, 2007

43. Starr JR, Collett BR, Gaither R, Kapp-Simon KA, Cradock MM, Cunningham ML, et al: Multicenter study of neurodevelopment in 3-year-old children with and without single-suture craniosynostosis. Arch Pediatr Adolesc Med 166:536-542, 2012

44. Stevens KJ, McCabe CJ, Brazier JE: Mapping between Visual Analogue Scale and Standard Gamble data; results from the UK Health Utilities Index 2 valuation survey. Health Econ 15:527-533, 2006

45. Tamburrini G, Caldarelli M, Massimi L, Santini P, Di Rocco $\mathrm{C}$ : Intracranial pressure monitoring in children with single suture and complex craniosynostosis: a review. Childs Nerv Syst 21:913-921, 2005

46. Thomas GP, Johnson D, Byren JC, Judge AD, Jayamohan J, Magdum SA, et al: The incidence of raised intracranial pressure in nonsyndromic sagittal craniosynostosis following primary surgery. J Neurosurg Pediatr 15:350-360, 2015

47. Torrance GW: Measurement of health state utilities for economic appraisal. J Health Econ 5:1-30, 1986

48. van Osch SM, Stiggelbout AM: The construction of standard gamble utilities. Health Econ 17:31-40, 2008

49. Virtanen R, Korhonen T, Fagerholm J, Viljanto J: Neurocognitive sequelae of scaphocephaly. Pediatrics 103:791-795, 1999

50. Zhang G, Tan H, Qian X, Zhang J, Li K, David LR, et al: A systematic approach to predicting spring force for sagittal craniosynostosis surgery. J Craniofac Surg 27:636-643, 2016

\section{Disclosures}

The authors report no conflict of interest concerning the materials or methods used in this study or the findings specified in this paper.

\section{Author Contributions}

Conception and design: Bezuhly, Kuta. Acquisition of data: Bezuhly, Kuta. Analysis and interpretation of data: Bezuhly, Kuta. Drafting the article: all authors. Critically revising the article: all authors. Reviewed submitted version of manuscript: all authors. Approved the final version of the manuscript on behalf of all authors: Bezuhly. Statistical analysis: Bezuhly, Kuta. Administrative/technical/material support: Bezuhly, McNeely, Walling. Study supervision: Bezuhly, McNeely, Walling.

\section{Correspondence}

Michael Bezuhly, Division of Plastic \& Reconstructive Surgery, Dalhousie University, IWK Health Centre, 5850/5980 University Ave., PO Box 9700, Halifax, NS B3K 6R8, Canada. email: mbezuhly@dal.ca. 